\title{
Spermatogonial behavior in rats during radiation-induced arrest and recovery after hormone suppression
}

\author{
Amanda V Albuquerque, Fernanda R C L Almeida, Connie C Weng ${ }^{1}$, Gunapala Shetty ${ }^{1}$, \\ Marvin L Meistrich ${ }^{1}$ and Hélio Chiarini-Garcia \\ Laboratory of Structural Biology and Reproduction, Department of Morphology, Institute of Biological Sciences, \\ Federal University of Minas Gerais, Avenida Antônio Carlos, 6627 - Pampulha, 31.270-901 Belo Horizonte, \\ Minas Gerais, Brazil and ${ }^{1}$ Department of Experimental Radiation Oncology, MD Anderson Cancer Center, \\ The University of Texas, Houston, Texas, USA \\ Correspondence should be addressed to H Chiarini-Garcia; Email: chiarini@icb.ufmg.br
}

\begin{abstract}
Ionizing radiation has been shown to arrest spermatogenesis despite the presence of surviving stem spermatogonia, by blocking their differentiation. This block is a result of damage to the somatic environment and is reversed when gonadotropins and testosterone are suppressed, but the mechanisms are still unknown. We examined spermatogonial differentiation and Sertoli cell factors that regulate spermatogonia after irradiation, during hormone suppression, and after hormone suppression combined with Leydig cell elimination with ethane dimethane sulfonate. These results showed that the numbers and cytoplasmic structure of Sertoli cells are unaffected by irradiation, only a few type $A$ undifferentiated $\left(A_{u n d}\right)$ spermatogonia and even fewer type $A_{1}$ spermatogonia remained, and immunohistochemical analysis showed that Sertoli cells still produced KIT ligand (KITLG) and glial cell line-derived neurotrophic factor (GDNF). Some of these cells expressed KIT receptor, demonstrating that the failure of differentiation was not a result of the absence of the KIT system. Hormone suppression resulted in an increase in $A_{\text {und }}$ spermatogonia within 3 days, a gradual increase in KIT-positive spermatogonia, and differentiation mainly to $A_{3}$ spermatogonia after 2 weeks. KITL (KITLG) protein expression did not change after hormone suppression, indicating that it is not a factor in the stimulation. However, GDNF increased steadily after hormone suppression, which was unexpected since GDNF is supposed to promote stem spermatogonial self-renewal and not differentiation. We conclude that the primary cause of the block in spermatogonial development is not due to Sertoli cell factors such (KITL \GDNF) or the KIT receptor. As elimination of Leydig cells in addition to hormone suppression resulted in differentiation to the $A_{3}$ stage within 1 week, Leydig cell factors were not necessary for spermatogonial differentiation.

Reproduction (2013) $146363-376$
\end{abstract}

\section{Introduction}

In boys and young men who have been affected by cancer, the successes of treatments that are deleterious to testicular function have made infertility an important issue. Over the past 30 years, advances in treatment of several cancers of young men, including testicular cancer, Hodgkin's lymphoma, and osteosarcoma, have resulted in considerable improvements in the outcomes of these diseases. However, the two main cancer treatments, chemotherapy and radiotherapy, induce prolonged or permanent azoospermia causing temporary or permanent infertility (Fossa \& Magelssen 2004, Meistrich et al. 2005, Shetty \& Meistrich 2005). The most sensitive testicular cells to chemotherapeutic drugs and radiation are the ones that are undergoing constant mitotic activity: the differentiating spermatogonia (Dym \& Clermont 1970, Lu \& Meistrich 1979, Kangasniemi et al. 1990). Death of these cells results in maturation depletion of later stages of germ cells and severe sperm count reduction, leading to the onset of infertility within several months. Subsequent recovery at later times is dependent on the spermatogonial stem cells.

In rodents, the spermatogonial stem cells have been identified morphologically as individual isolated cells called A single $\left(A_{s}\right)$ spermatogonia (de Rooij 1998). When these cells divide without complete separation of their cytoplasm, they form A paired spermatogonia $\left(A_{p r}\right)$, which undergo further mitotic divisions, forming chains of cells known as $A$ aligned spermatogonia $\left(A_{a l}\right)$. All these cells are often called type $A$ undifferentiated $\left(A_{\text {und }}\right)$ spermatogonia as they have similar morphology to the $A_{s}$ cells. When the type $A_{a l}$ spermatogonia differentiate, they form $A_{1}$ differentiating spermatogonia, which then undergo an extensive and precisely timed sequence of mitotic divisions begins producing $A_{1}, A_{2}, A_{3}$, and $A_{4}$, intermediate and $\mathrm{B}$ spermatogonia. The differentiating spermatogonia are most sensitive to the cytotoxic insults, but the undifferentiated spermatogonia, particularly the 
$\mathrm{A}_{\mathrm{s}}$, have lower rates of division and can survive moderate doses of cytotoxic insults. If they survive the cytotoxic insults, spermatogenesis recovery can occur naturally from the stem cells. Thus, the eventual recovery of sperm production after insults depends to a large extent on the survival of the spermatogonial stem cells and their functional ability to proliferate and differentiate, providing again the adequate number of type $A$ differentiating spermatogonia for the further steps of the process of spermatogenesis.

A variety of testicular toxic insults, such as radiation (Kangasniemi et al. 1996), procarbazine (Meistrich et al. 1999), and others (reviewed in Meistrich \& Shetty (2003)), induce seminiferous tubule atrophy in rats despite the presence and persistence of undifferentiated type A spermatogonia that appear to be blocked from further differentiation. In many of these cases, the suppression of testosterone and follicle-stimulating hormone ( $\mathrm{FSH}$ ) with gonadotropin-releasing hormone $(\mathrm{GNRH})$ analogs stimulated spermatogonial differentiation, resulting in spermatogenic progression (Meistrich \& Shetty 2003). In addition, although spermatogonial stem cells transplanted into irradiated rats can colonize along the basement membrane of seminiferous tubules, they fail to differentiate, unless hormones are suppressed (Zhang et al. 2007). Such studies demonstrated that some of the somatic cells forming the stem cell niche that controls many spermatogonial events can be damaged by radiation and their function rescued by hormone suppression.

In previous studies (Meistrich et al. 1999, Shuttlesworth et al. 2000), the block in type A spermatogonial differentiation and spermatogenesis recovery following hormone suppression was evaluated considering cell proliferation, clonal size, apoptosis, and appearance of differentiated cells as well as increases in testis weight, sperm count, and fertility. Gene expression profiles in the irradiated rats and irradiated rats with hormone suppression have also been analyzed (Zhou et al. 2010, 2011). In this study, we have extended the characterization of the kinetics and molecular events of spermatogonial differentiation in rats during spermatogenic recovery after testis irradiation and hormone suppression with a GNRH antagonist (GNRH-ant), using morphological (light and transmission electron microscopy) and stereological approaches and molecular markers (e.g., KIT). The light microscopy techniques that we developed were able to morphologically distinguish the spermatogonial subtypes - from type A undifferentiated up to type B spermatogonia (Chiarini-Garcia et al. 2003). Additionally, molecular expression of known factors produced by Sertoli cells, such as glial cell line-derived neurotrophic factor (GDNF) and Kit ligand (KITL (KITLG), formerly known as stem cell factor, SCF), which regulate stem spermatogonial self-renewal (Meng et al. 2000) and spermatogonial differentiation (Ohta et al. 2000), respectively, were evaluated and related to the spermatogonial counts.

\section{Materials and methods}

\section{Animals}

$\mathrm{LBNF}_{1}$ male rats were obtained from Harlan-Sprague Dawley (Indianapolis, IN, USA) and housed at the MD Anderson Cancer Center facilities under a $12 \mathrm{~h}$ light: $12 \mathrm{~h}$ darkness photoperiod and allowed food and water ad libitum. All procedures were approved by the MD Anderson Institutional Animal Care and Use Committee and the American Association for the Accreditation on Laboratory Animal Care.

\section{Irradiation}

Rats, at $\sim 10$ weeks of age, were anesthetized and all, except for unirradiated controls, were irradiated to the lower part of the body with a single dose of $6 \mathrm{~Gy}{ }^{60} \mathrm{Co}$ gamma radiation as described previously (Meistrich \& Kangasniemi 1997, Porter et al. 2006).

\section{Treatments}

The hormonal suppression treatment was initiated 10 weeks after irradiation. Acyline, a GNRH-ant (obtained from National Institutes of Health-National Institute of Child Health and Human Development, Bethesda, Maryland, USA), was freshly prepared in sterile water before each use and a dose of $1.5 \mathrm{mg} / \mathrm{kg}$ was injected s.c. weekly for 6 weeks. Furthermore, to reduce action of residual intratesticular testosterone levels, these irradiated rats received four s.c. silastic implants $(20 \mathrm{~cm}$ total length) containing flutamide (Sigma-Aldrich; Porter et al. 2009, Zhou et al. 2010). Additionally, to evaluate the effects of absence and Leydig cell factors, the Leydig cells were destroyed after a single i.p. dose $(75 \mathrm{mg} / \mathrm{kg})$ of ethane dimethane sulfonate (EDS; Bartlett et al. 1986), synthesized at MD Anderson by Dr William Bornmann).

\section{Experimental designs}

Two separate experiments were performed as illustrated in Fig. 1.

\section{Experiment I: cell counts and molecular events of spermatogonial differentiation}

To analyze the events of spermatogonial differentiation at different times after stimulation of differentiation with hormone suppression, 26 rats were given a single dose of $6 \mathrm{~Gy}$ irradiation. As a control (group C, $n=5$ ), age-matched, untreated, unirradiated rats were killed at the same time points as the irradiated, hormone-suppressed rats. Six rats that were irradiated (group $X, n=6$ ) were not given any hormone treatment and were assessed at 11 and 16 weeks after irradiation, which corresponded to 1 and 6 weeks after the beginning of treatment in the hormone-suppressed group. Intermediate time points were not taken because previous studies demonstrated that no changes in testicular histology, repopulation indexes, labeling indexes, and serum hormone levels occurred between 10 and 30 weeks after irradiation (Kangasniemi et al. 1996). The results of this study also showed 
Experiment I

Davidson's fluid fixative: methacrylate (light microscopy morphometry) and paraffin (immunohistochemistry)
Week 0
Week 10
Week 16

10 wk LBNF1 rats

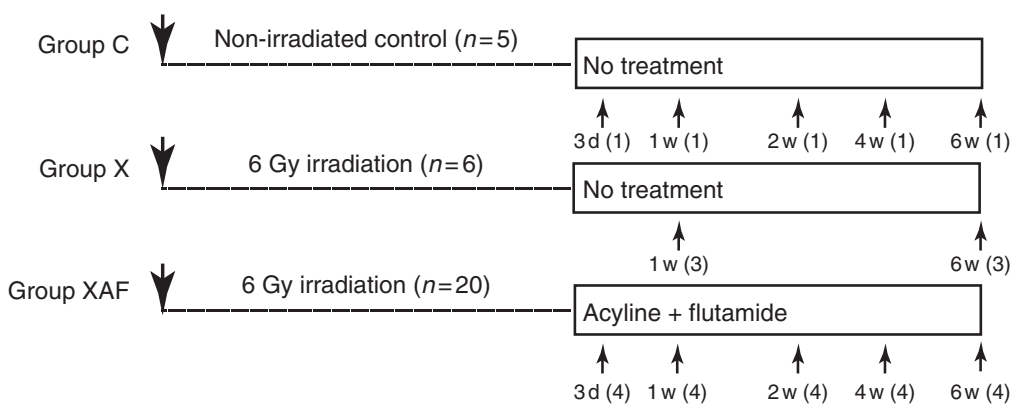

Experiment II

Glutaraldehyde fixative: Araldite (light microscopy morphometry and electron microscopy)

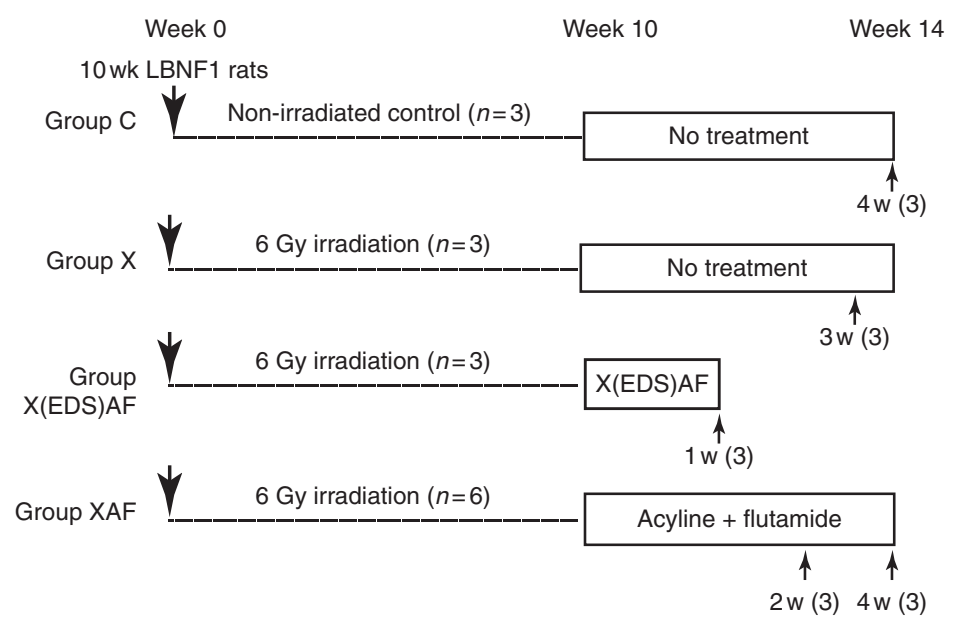

Figure 1 Experimental designs.

no significant differences between the rats assayed at 11 and 16 weeks after irradiation, and hence, the results for the two time points were averaged. Ten weeks after irradiation (considered as time zero), the remaining 20 rats were treated with weekly injections of GNRH-ant and implantation of flutamide capsules (group XAF) and were killed at times from 3 days to 6 weeks after starting hormone suppression.

Testes were fixed by vascular perfusion (Chiarini-Garcia \& Meistrich 2008) with Davidson's fluid modified as described by Latendresse et al. (2002). After the perfusion procedure, each testis was weighed with the tunica albuginea intact. They were carefully sliced into two pieces and immersed in $70 \%$ ethanol and kept under $4{ }^{\circ} \mathrm{C}$ until the embedding procedure. For histomorphometrical evaluation of germ and Sertoli cell numbers, half of the tissue was embedded in glycol methacrylate (GMA) resin (JB4, Polysciences, Inc., Warrington, PA, USA), and $4 \mu$ m-thick sections were stained with toluidine blue-borate (Chiarini-Garcia et al. 2011). The other half was embedded in paraffin and sectioned at $5 \mu \mathrm{m}$ thickness for immunohistochemical analysis.

Tubular diameter. Slides of GMA-embedded, Davidson's fluidperfused tissues were used for measurement of 20 nearly circular tubular cross sections per animal, randomly chosen at $400 \times$ magnification, using a ruler fitted in a $10 \times$ eyepiece, calibrated with a micrometer slide. When the tubular sections were slightly oval, only the smaller diameter was measured.

Absolute counts of Sertoli cells and type A spermatogonia. Stereological studies were performed to obtain the absolute numbers of Sertoli cells and type A spermatogonia in GMAembedded, Davidson's fluid-fixed testes from the irradiated $(X)$ and control (C) groups. As it was not possible to distinguish the A spermatogonial subtypes in glycol methacrylate-embedded material, they were considered as a whole. The numbers of each cell type were calculated, as described previously (Drumond et al. 2011).

First, the weight of the testicular parenchyma was calculated based on the measurements taken on other animals of the same strain obtained after removal of interstitial fluid and tunica albuginea (Porter et al. 2006). For control animals, the parenchymal weight was $96.8 \%$ of the testicular weight, and for the irradiated rats, it was only $64.6 \%$ (M L Meistrich, unpublished results) because of extensive edema after irradiation. Then, the absolute volume of the testicular parenchyma was calculated based on a testicular density of $1.0 \mathrm{~g} / \mathrm{cm}^{3}$ (Sinha Hikim et al. 1988).

Next, using the point counting method, $\sim 4410$ intersections distributed in ten randomly selected fields per animal (two to 
three fields per histological section) were counted as being over the seminiferous epithelium or the rest of testicular parenchyma. The volume density of the seminiferous epithelium was obtained by dividing the sum of points falling on the seminiferous epithelium by the total number of points over the tissue, and the volume of the seminiferous epithelium was estimated by multiplying this by the volume to the testis parenchyma.

Point counting of $\sim 18000$ intersections in 40 randomly selected fields for each animal (four to five fields per histological section), as being over Sertoli cell nucleoli, type A spermatogonial nuclei, or over other areas of the seminiferous epithelium was similarly employed to determine the volume densities of these cell components. The total volume of all the Sertoli cell nucleoli and spermatogonial nuclei was calculated by multiplying their volume densities by the absolute volume of the seminiferous epithelium.

The average volumes of individual Sertoli cell nucleoli or spermatogonial nuclei were determined from their diameters measured with a ruler in the eyepiece, as described previously. Finally, the total number of these cells was calculated by dividing the total volumes of Sertoli cell nucleoli or type A spermatogonia by the individual volumes of each Sertoli nucleolus or spermatogonial nucleus respectively.

Sertoli and germ cell numbers per tubule cross section. The numbers of Sertoli cell nucleoli and germ cell nuclei, from spermatogonia up to diplotene primary spermatocytes, were counted in 50 randomly chosen seminiferous tubule cross sections in control and in 100 seminiferous tubule cross sections per animal for each time point of the hormone suppression (XAF), in irradiated-only (X) and control (C) groups, using the Davidson's fluid-perfused, GMA-embedded tissues. Results were expressed as counts per tubule cross section.

Immunohistochemistry. In order to analyze some molecular changes after irradiation and during subsequent hormone suppression, slides of the paraffin-embedded, Davidson's fluidperfused tissues were immunostained for the proliferation marker, minichromosome maintenance protein 7 (MCM7 mouse MAB, Abcam, Cambridge, MA, USA, ab79802), the Sertoli cell juxtacrine factors GDNF (rabbit polyclonal, Santa Cruz, Dallas, TX, USA, D-20, sc: 328) and KITLG (rabbit polyclonal antibody against C-terminus, gift of Dr Shayu Deshpande, Deshpande et al. (2010)), and the KIT receptor (c-kit, goat polyclonal Santa Cruz, M-14, sc: 1494). The sections were subjected to antigen retrieval and then incubated with a blocking solution. The slides were incubated with primary antibodies overnight at $4{ }^{\circ} \mathrm{C}$ in a humidified chamber. After washing in PBS, the slides were incubated with Alexa Flour 488-labeled antirabbit IgG for KITLG and GDNF, with Alexa Fluor 594-labeled anti-goat IgG for KIT, or with a secondary biotinylated antibody for MCM7. The biotinylated secondary antibody was detected by the avidin-biotin-peroxidase complex method with diaminobenzidine using the Vectastain elite ABC kit (Vector Laboratories, Burlingame, CA, USA). Control slides were prepared without the addition of primary antibodies (Supplementary Figure 1, see section on supplementary data given at the end of this article).

For quantification of GDNF and KITL concentration in Sertoli cells, fluorescence images from a set of slides from different animals, stained at the same time, were photographed using the same exposure time for all frames. Photomicrographs of ten randomly chosen cross-sectioned seminiferous tubules per animal were analyzed using the NIH Image J (Image Processing and Analysis in Java, v1.45s) Software. The average fluorescence intensity (mean pixel intensities) of the Sertoli cell cytoplasm, identified as the region within the tubule excluding the nuclei of the cells, the lumen, germ cells, and vacuolar areas, was measured (Supplementary Figure 2, see section on supplementary data given at the end of this article). Next, the fluorescence due to nonspecific binding of antibody to tissues was measured by taking the average fluorescence intensity over the region of the peritubular myoid cells and basement membrane (PM). As the variations between slides appeared to be a result of background fluorescence (BG) over areas with no tissue (spaces in the interstitium due to tissue contraction), most probably due to fluctuations in lamp intensity, both the Sertoli cell (SF) and myoid/basement membrane (PM) fluorescence levels were normalized between slides by dividing them by the background fluorescence (BG). Then the difference between the normalized Sertoli cell fluorescence and the normalized non-specific myoid/basement membrane fluorescence was calculated to determine the corrected, specific Sertoli cell immunofluorescence intensity.

MCM7 + cells and KIT + cells were counted in 50 randomly chosen, nearly circular seminiferous tubules per animal in the irradiated-only animals (X) and the hormone-suppressed (XAF) group.

Experiment II: kinetics of spermatogonial differentiation after hormone suppression and ultrastructural studies

To morphologically distinguish the spermatogonial types ( $A_{u n d}, A_{1}$, $A_{2}, A_{3}, A_{4}$, In, $B$ spermatogonia) and assess ultrastructural changes in germ and Sertoli cells and tubule structure, 12 rats were treated with a single dose of 6 Gy irradiation as in experiment I (Fig. 1). Age-matched control rats (group C, $n=3$ ), without any treatment, were included for comparison. Three irradiated rats (group X), without hormone suppression, were killed at 3 weeks after the beginning of the hormonal treatment of the suppressed group. To evaluate the combined effects of Leydig cell elimination and hormone suppression on spermatogonial differentiation, three of the irradiated rats $(\mathrm{X}(\mathrm{EDS}) \mathrm{AF}$ group) were treated with $\mathrm{EDS}$ at 10 weeks after irradiation and then hormonally suppressed with acyline and flutamide and analyzed 1 week later. The remaining six irradiated rats were treated, starting 10 weeks after irradiation, with acyline and flutamide (XAF group, $n=3 /$ time point), as in experiment I, for 2 or 4 weeks. Animals in all these groups were perfusion fixed with $5 \%$ glutaraldehyde in $0.05 \mathrm{M}$ cacodylate buffer ( $\mathrm{pH}$ 7.4). Testes were removed, weighed, and sliced into small slabs. Fragments were post-fixed in osmium tetroxide/ potassium ferrocyanide mixture and embedded in a plastic resin, Araldite 502 (EMS, Hatfield, PA, USA).

Spermatogonial differentiation kinetics. To assess the kinetics of spermatogonial differentiation, $1 \mu \mathrm{m}$-thick sections were obtained from testis fixed with glutaraldehyde/osmium and embedded in Araldite and stained with toluidine blue-borate for light microscopy studies. This method, which we previously called high-resolution light microscopy, allowed us to recognize the different spermatogonial subtypes by their morphological features. 
Nuclei of all spermatogonial subtypes $\left(\mathrm{A}_{\text {und }}\right.$ to $\left.\mathrm{B}\right)$ and Sertoli cell nucleoli were counted in 50 randomly chosen seminiferous tubule cross sections in each animal. Considering that the nuclei (and nucleoli) have different diameters, the Abercrombie (1946) correction for bias in the estimation of nuclear numbers in cross sections was applied. For that, ten diameters of each germ cell subtype nuclei and Sertoli cell nucleoli were measured. The Abercrombie (1946) formula was applied to obtain corrected counts, which were used to calculate the ratio of germ cells per 100 Sertoli cell nucleoli, an accepted method for comparison of germ cell counts (Dym \& Clermont 1970).

Transmission electron microscopy. To evaluate the spermatogonial and Sertoli cell ultrastructure after irradiation and during hormone suppression, sections were obtained at $70 \mathrm{~nm}$ thickness from the Araldite resin blocks used for light microscopy analysis. These ultrathin sections were collected in cooper grids, stained with uranyl acetate and lead citrate, and observed under the transmission electron microscope (Zeiss EM-10). The spermatogonial identification at the ultrastructural level was based on that of Chiarini-Garcia \& Russell (2002).

\section{Statistical analysis}

All variables measured were tested for normality prior to analyses, using the univariate procedure of the Statistical Analysis System (SAS Institute, Cary, NC, USA). The values of variables were compared between the control and irradiatedonly group with a $t$-test with $P<0.05$ being considered significant. Comparisons between the irradiated-only and irradiated hormone-suppressed groups were done by ANOVA. In the event that significant treatment effects were established, multiple comparisons were performed using probability of differences adjusted by Tukey-Kramer (SAS 2001) with $P<0.05$ being considered significant. In the tables and graphs, data are reported as means and S.E.M.

\section{Results}

\section{Experiment I}

\section{Body and testis weight}

The body weight did not change after irradiation or after hormonal suppression. Meanwhile, radiation had a dramatic effect on testis weight, reducing it from $1.88 \pm$ $0.01 \mathrm{~g}$ in the untreated control group to $0.56 \pm 0.02 \mathrm{~g}$ (similar at both time points assessed), about $30 \%$ of the weight for controls $(P<0.05)$, in the irradiated $(X)$ group. During the subsequent hormone suppression with acyline plus flutamide, the weights of irradiated testes progressively declined further ( 3 days: $0.52 \pm 0.02 \mathrm{~g}$, 1 week: $0.47 \pm 0.01 \mathrm{~g}$, 2 weeks: $0.39 \pm 0.02 \mathrm{~g}$, 4 weeks: $0.36 \pm 0.01 \mathrm{~g}$, and 6 weeks: $0.34 \pm 0.01 \mathrm{~g}$ ).

\section{Morphological and stereological analysis}

Testicular atrophy after irradiation or during the subsequent hormone suppression was first analyzed using seminiferous tubule diameters. The mean tubular diameters in the irradiated-only group $(192 \pm 2 \mu \mathrm{m})$ were significantly lower than those of the untreated controls $(355 \pm 3 \mu \mathrm{m})$. The hormone suppression produced a further progressive decrease in the tubular diameter ( 3 days: $192 \pm 1 \mu \mathrm{m}, 1$ week: $188 \pm 3 \mu \mathrm{m}$, 2 weeks: $183 \pm 2 \mu \mathrm{m}, 4$ weeks: $174 \pm 3 \mu \mathrm{m}$, and 6 weeks: $166 \pm 4 \mu \mathrm{m})(P<0.05)$.

To determine whether there was an effect of irradiation on Sertoli cell number, a stereological approach was applied. The total Sertoli cell number per testis was shown not to be changed significantly as a result of irradiation; in the control animals, it was $49 \pm 4 \times 10^{6}$ and in the irradiated-only animals, $40 \pm 2 \times 10^{6}$.

Studies of changes in germ cell numbers were performed using counts of cells per tubular cross section, which is valid when there is not much longitudinal shrinkage or expansion of the tubules. There was only a modest shrinkage after irradiation as indicated by a $22 \%$ increase in numbers of Sertoli cell nucleoli per cross section in irradiated-only compared with control rats (Table 1). Radiation produced dramatic effects on germ cells with a 20-fold reduction in the numbers of spermatogonia per tubule cross section and a block in their differentiation so that no spermatocytes were observed even at 11-16 weeks after irradiation (Table 1). Stereological methods confirmed that there was a marked decrease in the numbers of type $A$ spermatogonia per testis to $3.1 \pm 0.4 \times 10^{6}$ in the irradiated-only animals compared with $20.0 \pm 2.6 \times 10^{6}$ in the control group $(P<0.05)$.

When hormones were suppressed with GNRH-ant and flutamide in the irradiated animals, the number of Sertoli cell nucleoli per tubule cross section did not change significantly so that spermatogonial numbers could be directly compared. Hormone suppression with acyline and flutamide produced an increase in the number of spermatogonia at 3 days and this number was maintained at twice the level of that in the irradiatedonly rats for the first 2 weeks (Table 1). Differentiation to the spermatocyte stage was first observed at 4 weeks after starting the hormone suppression, and by 6 weeks, an appreciable number of pachytene primary spermatocytes were found as the most advanced germ cells in the repopulated seminiferous tubules (Table 1 ).

\section{Immunohistochemical analysis}

To test whether the spermatogonia observed after irradiation were expressing a proliferation marker; we performed immunohistochemistry for MCM7 after irradiation and during hormone suppression (Fig. 2). In control rats, all spermatogonia and primary spermatocytes until the mid-pachytene stage were MCM7positive; a weak signal was observed in later pachytene spermatocytes and no signal in Sertoli cells, round, and elongated spermatids (Fig. 2A). In irradiated-only rats and those with hormone suppression as well, 
Table 1 Numbers of Sertoli and germ cells per tubular cross section in control (C), irradiated (X) and hormone-suppressed (XAF) rats after different times of $\mathrm{GnRH}$-ant + flutamide administration. Sertoli cells were only scored if the nucleolus was present in the section.

\begin{tabular}{|c|c|c|c|c|c|c|c|}
\hline Treatment & Sertoli & $\begin{array}{c}\text { Total } \\
\text { spermatogonia }\end{array}$ & PL & $\mathbf{L}$ & $\mathbf{Z}$ & $\mathbf{P}$ & D \\
\hline $\mathrm{C}$ & $12.28 \pm 0.45$ & $8.10 \pm 0.21$ & $5.28 \pm 0.14$ & $6.50 \pm 0.78$ & $5.74 \pm 0.86$ & $33.84 \pm 1.58$ & $6.70 \pm 2.96$ \\
\hline$x$ & $13.94 \pm 0.53$ & $0.52 \pm 0.03^{*}$ & $0^{*, a}$ & $0^{*, a}$ & $0^{*, a}$ & $0^{*, a}$ & $0^{*, a}$ \\
\hline XAF 3 days & $12.24+0.49$ & $0.73+0.04$ & $0^{\mathrm{a}}$ & $0^{a}$ & $0^{\mathrm{a}}$ & $0^{\mathrm{a}}$ & $0^{\mathrm{a}}$ \\
\hline XAF $1 \mathrm{w}$ & $12.67 \pm 0.67$ & $1.08 \pm 0.18$ & $0^{\mathrm{a}}$ & $0^{\mathrm{a}}$ & $0^{\mathrm{a}}$ & $0^{\mathrm{a}}$ & $0^{\mathrm{a}}$ \\
\hline XAF 2w & $12.97+0.53$ & $1.14+0.03$ & $0^{\mathrm{a}}$ & $0^{\mathrm{a}}$ & $0^{\mathrm{a}}$ & $0^{\mathrm{a}}$ & $0^{\mathrm{a}}$ \\
\hline XAF $4 w$ & $14.15+0.60$ & $3.05+0.46$ & $0.52+0.27^{\mathrm{a}}$ & $0.08+0.05^{\mathrm{a}}$ & $0.14+0.04^{\mathrm{a}}$ & $0.13+0.06^{\mathrm{a}}$ & $0^{a}$ \\
\hline XAF $6 w$ & $13.92 \pm 0.60$ & $2.98 \pm 0.29$ & $4.46 \pm 0.37^{\mathrm{b}}$ & $1.16 \pm 0.10^{b}$ & $0.91 \pm 0.10^{\mathrm{b}}$ & $1.76 \pm 0.66^{\mathrm{b}}$ & $0.08 \pm 0.03^{b}$ \\
\hline
\end{tabular}

Values are mean \pm S.E.M. Asterisks indicate a significant difference $(P \leq 0.05)$ between the $C$ and $X$ groups $(t$-test). Different letters in the same column indicate a significant difference $(P \leq 0.05)$ between $X$ and individual XAF groups, using Tukey's test. Total spermatogonia (type A spermatogonia + type intermediate+type B spermatogonia); PL, preleptotene; L, leptotene; Z, zygotene; P, pachytene; D, diplotene.

all spermatogonia were also MCM7-positive, indicating that they were proliferative (Fig. 2B). The clones of spermatogonia observed after 2 weeks of treatment had a tendency to appear as clusters (Fig. 2C), but after 4 weeks, they were observed spread out along the basal membrane (Fig. 2D). As expected, the MCM7-positive cell number was low in irradiated rats and progressively increased during hormone suppression (Fig. 2E), paralleling the increase in spermatogonia and primary spermatocytes (Table 1).

The expression of KIT, a differentiating spermatogonial marker, was examined next. In control animals, most of the spermatogonia were stained for KIT; however, few unstained spermatogonia, usually in stages II-VI,

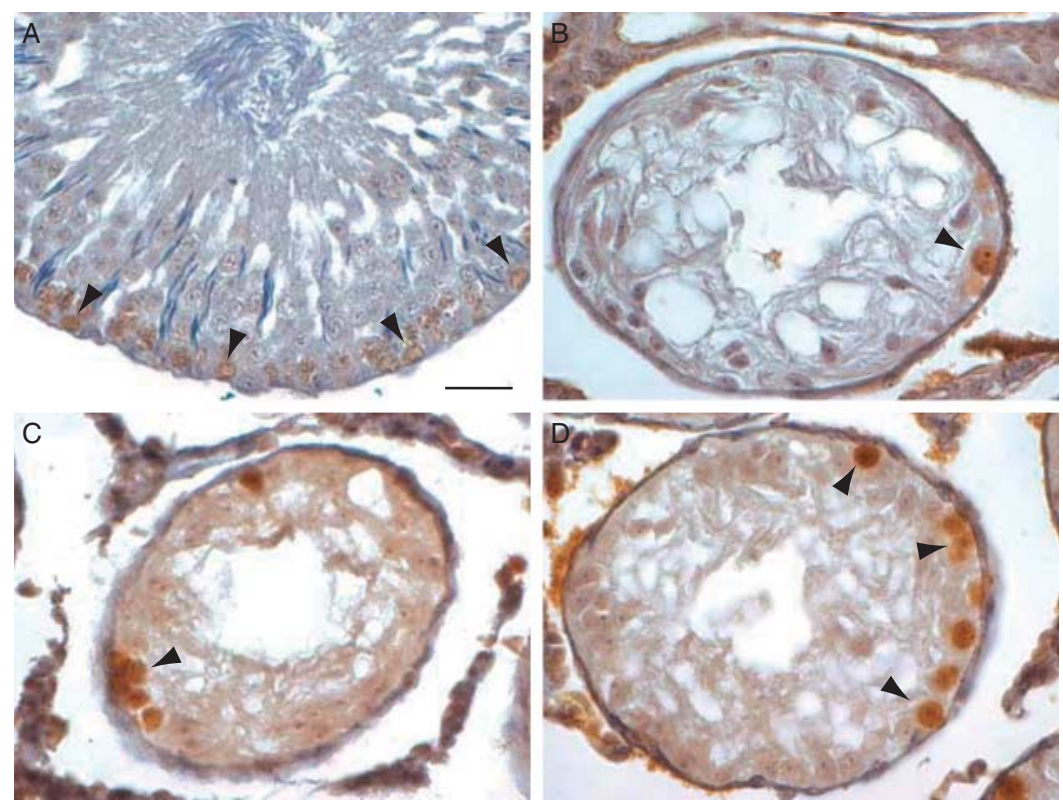

E

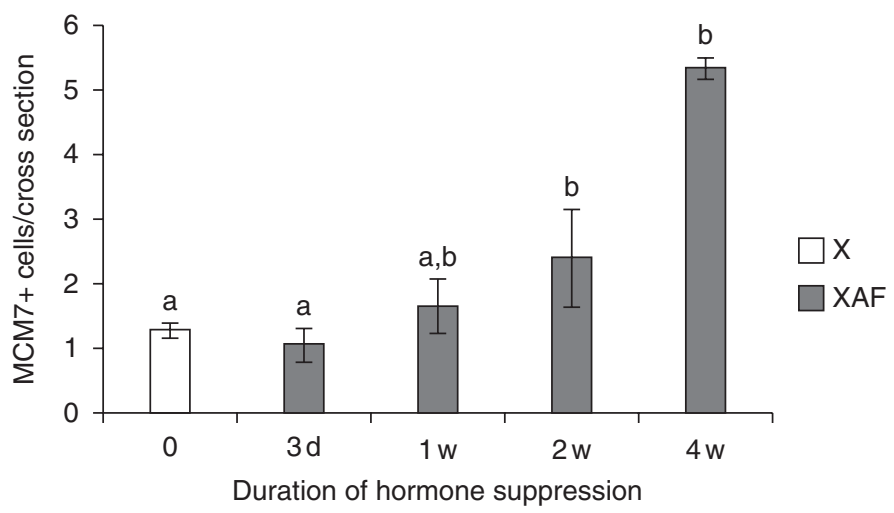

Figure 2 Immunostaining of MCM7-positive cells in control rats $(A)$, irradiated-only rats $(B)$, and in rats after irradiation and treatment with acyline plus flutamide for 2 (C) and 4 (D) weeks. Arrowheads point to MCM7-positive cells. At 2 weeks, the spermatogonia sometimes appear to be clustered whereas at 4 weeks they are more generally spread along the basement membrane. Bar: $25 \mu \mathrm{m}$. (E) MCM7-positive cells per tubular cross section in irradiated-only rats $(\mathrm{X})$ and after acyline plus flutamide therapy (XAF). Different letters indicate a significant difference $(P<0.05)$ between the $\mathrm{X}$ and $\mathrm{XAF}$ groups using Tukey's test. 
recognized using DAPI fluorescence, were observed (not shown). In the rats receiving only irradiation, about half of the spermatogonia were KIT-negative and the rest were KIT-positive (Fig. 3A and B). The presence of KITpositive spermatogonia in the seminiferous epithelium after the insult indicates that the spermatogonial differentiation block after irradiation is not due to the absence of the KIT receptor protein. The hormonal suppression gradually increased the numbers of KITpositive cells from 1 up to 4 weeks of treatment (Fig. 3C). Comparing the KIT-positive spermatogonial cells with the morphological findings, we observed an increasing percentage of KIT-positive cells among the spermatogonia during hormone suppression (Fig. 3D).

To evaluate the effects of irradiation and acyline plus flutamide treatment on the expression of Sertoli cell factors affecting spermatogonial development, GDNF and KITL protein concentrations were assessed by immunofluorescence. In control animals, GDNF protein fluorescence was specific to the Sertoli cell cytoplasmic domain (Fig. 4A). The fluorescence intensity changed as the surrounding germ cells progressed through the stages of the cycle, with the highest intensity observed at stages XIII-I. In irradiated animals with tubular atrophy, there is no longer a seminiferous epithelial cycle and the GDNF protein concentrations appeared to be the same in all tubules (Fig. 4B). Following the initiation of hormone suppression, the GDNF protein concentrations over Sertoli cells appeared to increase progressively from 3 days of treatment up to 4 weeks of hormone suppression (Fig. 4C), at which time the increase became significant $(P<0.05$, Fig. 4D).

Similar studies of the expression of KITL protein, using an antibody specific for the cytoplasmic terminal region, confirms that in control animals, it accumulates in the basolateral region of Sertoli cells (Fig. 5A), as described recently (Deshpande et al. 2010). In irradiated-only animals, the KITL protein is fully maintained and appears to be uniformly distributed over Sertoli cell cytoplasm (Fig. 5B), but after 4 weeks of hormone suppression, it appears again to be stronger basally (Fig. 5C). Hormone suppression did not significantly affect the concentrations of KITL protein in the Sertoli cells of irradiated rats (Fig. 5D).
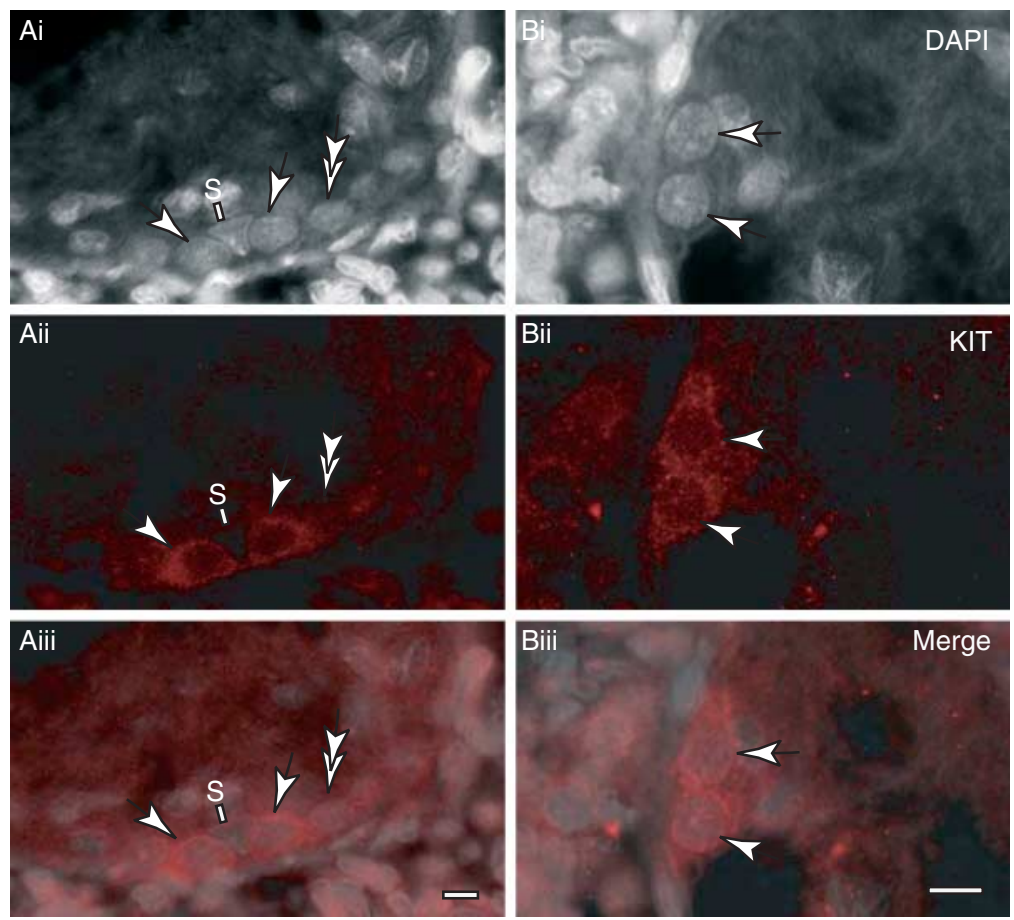

C

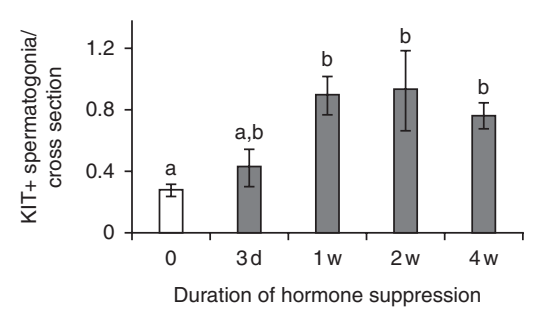

D

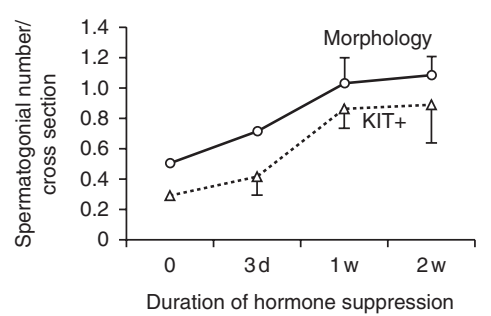

Figure 3 ( $A$ and $B$ ) KIT immunofluorescence of spermatogonia in irradiated-only animals. ( $\mathrm{Ai}$ and $\mathrm{Bi}$ ) DAPI; (Aii and Bii) KIT immunofluorescence; (Aiii and Biii) merge. KIT-positive (arrowheads) and KIT-negative (double arrowhead) spermatogonia are indicated; S, Sertoli cell. Bars: A and B $10 \mu \mathrm{m}$. (C) KIT-positive cells per tubular cross section in irradiated-only $(X$, white bar) and after different times of treatment with acyline+ flutamide (XAF, grey bars). No significant differences were found between the irradiated-only animals analyzed at two different time points and the values are combined and plotted at ' 0 ' (no hormone suppression). Different letters indicate a significant difference $(P<0.05)$ among $\mathrm{X}$ and XAF groups using Tukey's test. After 4 weeks of treatment, the few pachytene cells observed were also but were excluded from the total counts. (D) Comparison between the total number of $\mathrm{KIT}+$ spermatogonia per cross section and the total number of morphologically identified in stained GMA-embedded sections. 

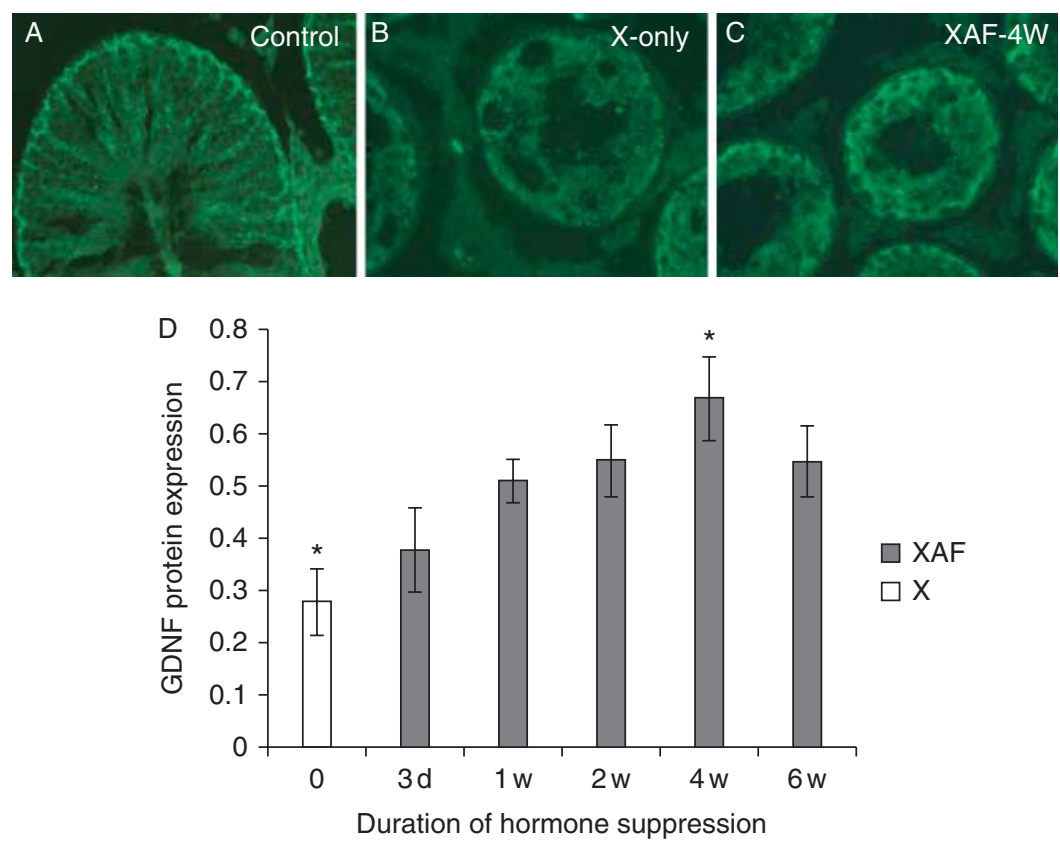

Figure 4 Immunofluorescence of GDNF within tubular cross sections in control (A), irradiated-only (B), and 4-week hormone-suppressed animals (C). (D) Quantification of the average specific GDNF immunofluorescence intensity over Sertoli cytoplasm in tubule cross sections in irradiated only $(X)$ and during hormone suppression with acyline + flutamide (XAF). No significant differences were found between the irradiated-only animals at two different time points and the values are combined and plotted at ' 0 ' (no hormone suppression). Asterisks indicate values among $\mathrm{X}$ and $\mathrm{XAF}$ groups that show a significant difference $(P<0.05)$ using Tukey's test.

\section{Experiment II}

Based on the results from experiment $\mathrm{I}$, in which progressive increases in spermatogonial numbers were observed after the initiation of hormone suppression, a second experiment was designed to assess the kinetics of spermatogonial differentiation using a light microscopic technique capable of identifying the different spermatogonial types.

\section{Body and testis weight}

As in experiment I, the body weight did not change after irradiation or after hormonal suppression. Radiation had the same dramatic effect on testis weight reducing it to $30 \%$

of the control value $(P<0.05)$ in the irradiated $(X)$ group (C: $1.86 \pm 0.03 \mathrm{~g} ; \mathrm{X}: 0.56 \pm 0.01 \mathrm{~g}$ ). The addition of EDS to the hormone suppression regimen decreased the testis weight more rapidly than hormone suppression alone, reducing it to $0.42 \pm 0.02 \mathrm{~g}$ after 1 week of treatment.

\section{Spermatogonial kinetics}

Sections of glutaraldehyde/osmium-fixed, Aralditeembedded tissues were analyzed by counting the numbers of different subtypes of spermatogonia and applying appropriate normalization and correction factors to obtain the relative numbers of those cells (Table 2). The remaining type A spermatogonia in the
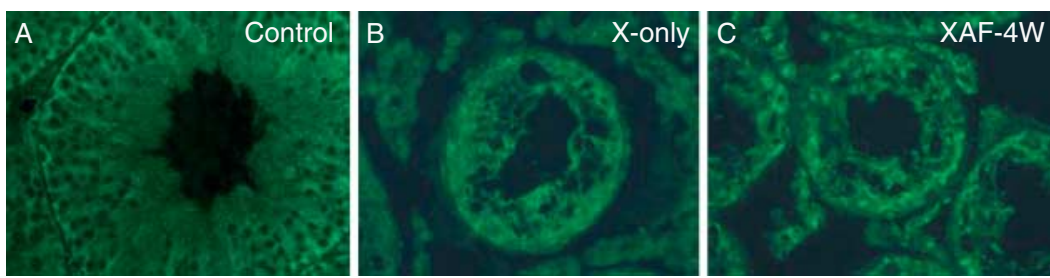

D

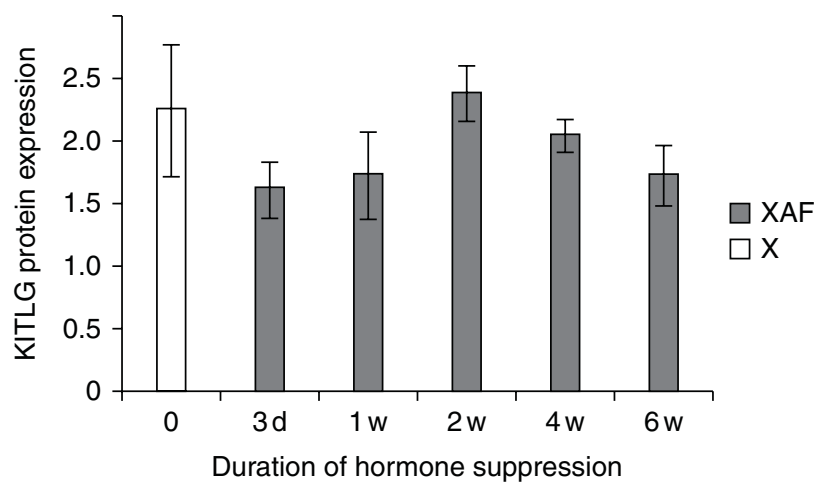

Figure 5 Immunofluorescence of KITL within tubular cross sections in control (A), irradiated-only (B), and 4-week hormone-suppressed animals (C). (D) Quantification of the average KITL immunofluorescence intensity in Sertoli cytoplasm in tubule cross sections in irradiated-only animals $(X)$ and during hormone suppression (XAF). No significant differences were found between the irradiated-only animals at two different time points and the values are combined and plotted at ' 0 ' (no hormone suppression). There were no significant differences between the different treatment groups $(P \geq 0.05)$. 
Table 2 Number of Sertoli cells, scored if the nucleolus was observed, per tubular cross section and numbers of spermatogonial subtypes per 100 Sertoli cell nucleoli in control rats $(\mathrm{C})$, irradiated rats $(\mathrm{X})$ and rats treated with $\mathrm{GnRH}$-ant + flutamide, without (XAF) or with EDS (X(EDS)AF). Cells were scored in glutaraldehyde/osmium-fixed, Araldite-embedded tissues and values have been already corrected for differences in diameters (Abercrombie 1946).

\begin{tabular}{|c|c|c|c|c|c|c|c|c|}
\hline Groups & Se & $A_{\text {und }}$ & $A_{1}$ & $A_{2}$ & $\mathbf{A}_{3}$ & $\mathbf{A}_{4}$ & In & B \\
\hline C & $1.67 \pm 0.05$ & $10.19 \pm 0.15$ & $1.60 \pm 0.45$ & $3.38 \pm 0.61$ & $3.65 \pm 0.56$ & $4.65 \pm 0.51$ & $8.28 \pm 0.86$ & $20.12 \pm 2.67$ \\
\hline$x$ & $2.41+0.10$ & $0.92+0.32^{*, a}$ & $0.24+0.07^{*, a}$ & $0^{*, a}$ & $0^{*}$ & $0^{*}$ & $0^{*}$ & $0^{*}$ \\
\hline$X(E D S) A F-1 w$ & $2.25 \pm 0.17$ & $1.91 \pm 0.34^{\mathrm{a}}$ & $0.77 \pm 0.06^{\mathrm{a}}$ & $0.27 \pm 0.03^{\mathrm{a}, \mathrm{b}}$ & $0.35 \pm 0.16$ & $0.11 \pm 0.06$ & $0.14 \pm 0.12$ & 0 \\
\hline$X A F-2 w$ & $2.31 \pm 0.13$ & $2.02 \pm 0.32^{\mathrm{a}}$ & $0.75 \pm 0.01^{\mathrm{a}}$ & $0.32 \pm 0.08^{\mathrm{a}, \mathrm{b}}$ & $0.26 \pm 0.05$ & $0.08 \pm 0.06$ & $0.27 \pm 0.22$ & $0.09 \pm 0.08$ \\
\hline$X A F-4 w$ & $2.73 \pm 0.08$ & $4.50 \pm 0.11^{b}$ & $2.87 \pm 0.25^{\mathrm{b}}$ & $1.74 \pm 0.12^{\mathrm{b}}$ & $0.99 \pm 0.23$ & $0.92 \pm 0.16$ & $0.07 \pm 0.03$ & $0.22 \pm 0.09$ \\
\hline
\end{tabular}

Values are mean \pm S.E.M. Asterisks indicate a significant difference $(P<0.05)$ between $\mathrm{C}$ and $\mathrm{X}$ group $(t$-test). Different letters in the same column indicate a significant difference $(P<0.05)$ between $\mathrm{X}$ and individual treated groups, using Tukey's test. $\mathrm{A}_{\mathrm{und}}$, undifferentiated type $\mathrm{A}$ spermatogonia; A1-A4, differentiating type A spermatogonia; In, intermediate spermatogonia; B, type B spermatogonia.

irradiated rats were primarily $\mathrm{A}_{\text {und }}$ spermatogonia and their numbers were still drastically decreased from control levels (Table 2); only few cells differentiated to the $A_{1}$ subtype (Fig. $6 B$ ).

The addition of a single dose of EDS at the start of the hormone-suppressive treatment (X(EDS)AF group) effectively eliminated the all Leydig cells (Fig. 6C) and resulted in rapid spermatogenesis recovery as indicated by the increase in spermatogonial subtypes observed after 1 week (Table 2).

Hormone suppression for 2 weeks increased the numbers of $\mathrm{A}_{\text {und }}$ spermatogonia by twofold and also supported initiation of further differentiation resulting in occasional cells of up to $B$ spermatogonial stage (Fig. 6D). Clones of type $A_{a l} / A_{1}$ spermatogonia (Fig. 6E) were frequently seen in the cross sections starting after 2 weeks of hormonal treatment. The numbers of cells in all stages of spermatogonial development progressively increased at 4 weeks of hormone suppression $(P<0.05)$. Although the $A_{1}$ spermatogonial number reached control levels at this time point, the numbers of subsequent spermatogonial subtypes, from type $A_{2}$ to $B$ spermatogonia (Fig. 6F and G), did not.

\section{Ultrastructure of germ and Sertoli cells}

Ultrastructural studies showed that after irradiation and the initiation of hormone treatment, the Sertoli cell nuclei became more elongated and highly infolded and had more heterochromatin close to the nuclear envelope (Fig. $7 \mathrm{C}$ and $\mathrm{E}$ ) compared with those from control rats (Fig. 7A). No other Sertoli cell organelles displayed significant abnormal morphological changes. The Sertoli-Sertoli junctions characterized by ectoplasmic specializations normally observed in control rats were still observed after irradiation. These junctions were observed more basally in the epithelium (Fig. 7C) when only Sertoli cells and no type A spermatogonia were present within that region of the seminiferous tubule. However, the ectoplasmic specialization appeared above the cells, when spermatogonia were present after hormone suppression (Fig. 7E), indicating that the barrier between basal and adluminal compartments may be preserved. Observations of the basal lamina after irradiation only and also with hormone suppression showed that it, sometimes along with an associated myoid cell, protruded into the seminiferous epithelium forming an invagination in the basal aspect of Sertoli cells and some spermatogonia (Fig. 7D and E). Ultrastructural examination of the spermatogonia along the basement membrane of irradiated and hormone-suppressed rats (Fig. 7B, D, and F) showed that, except for the invaginations described above, the cells apparently had normal nuclear and cytoplasmic morphology, as described previously by Chiarini-Garcia \& Russell (2002).

\section{Discussion}

In this study, we have further characterized the spermatogonia present after radiation induces a block in their differentiation in $\mathrm{LBNF}_{1}$ rats and after their differentiation is restored by hormone suppression. Here, we used glutaraldehyde fixation and Araldite embedding to recognize each spermatogonial subtype by morphology at the light microscope level. Radiation or radiation followed by hormone suppression did not alter the morphology (Chiarini-Garcia et al. 2003) or ultrastructure (Chiarini-Garcia \& Russell 2002) of the spermatogonia as they appeared as described previously. We noted that after irradiation alone, most of the spermatogonia were undifferentiated type $A$ but about $20 \%$ were $A_{1}$. As it is the longer chains of undifferentiated clones that transform into $A_{1}$ spermatogonia, this is consistent with and supports a previous observation in whole-mounted tubules that most of the spermatogonia were type $A$ as single cells or as pairs and only a few were seen as longer clones (Shuttlesworth et al. 2000). Hormone suppression induced differentiation to the B spermatogonial stage within 2 weeks and to the spermatocyte stage within 4 weeks.

Although stem spermatogonia do not express KIT, the undifferentiated type A spermatogonia normally become KIT-positive cells just before they initiate their differentiation to $A_{1}$ spermatogonia. In irradiated rat testes without any hormone suppression, we observed appreciable numbers of KIT-positive spermatogonia, some of which could be $\mathrm{A}_{1}$ and others must be $\mathrm{A}_{\text {und }}$. In a previous 

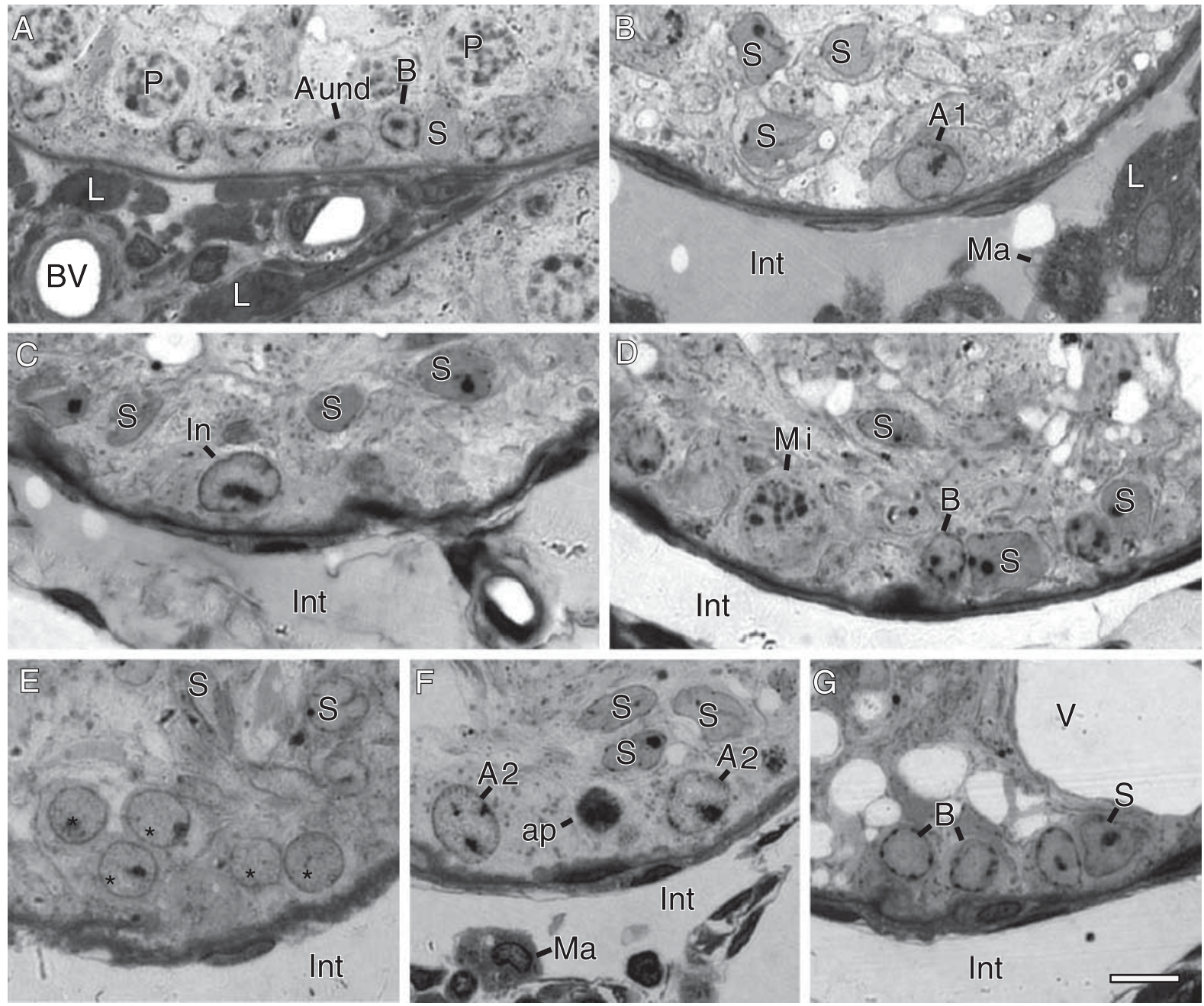

Figure 6 Light micrographs of spermatogonia in glutaraldehyde/osmium-fixed, Araldite-embedded tissue from (A) control, showing undifferentiated spermatogonia $\left(A_{\text {und }}\right)$ and all differentiated germ cells and $(B)$ an irradiated rat, in which type $A 1$ spermatogonia $\left(A_{1}\right)$ are the most advanced germ cells. The $A_{1}$ spermatogonia present a larger and more rounded nucleus than the $A_{u n d}$, with more finely granular nucleoplasm and a more reticulated nucleolus protruding centrally from nuclear envelope. After irradiation and hormonal suppression, with EDS for 1 week (C) or without EDS for 2 weeks (D), the most advanced germ cells were intermediate and type $B$ spermatogonia respectively. After 4 weeks, clones of $A_{a l}$ spermatogonia were frequent $(E$, asterisks) and all spermatogonial subtypes up to type $B$ spermatogonia were seen ( $F$ and $G$ ). $A_{2}$ spermatogonia $(F)$ were distinguished from earlier-stage cells by the increase in flecks of heterochromatin along nuclear envelope and nucleolus being more reticulated and irregular than $A_{1}$ spermatogonia. $A_{u n d}$ undifferentiated type $A$ spermatogonia; $A_{1}, A_{2}$, type $A$ differentiating spermatogonia; In, intermediate spermatogonia; $B$, type $B$ spermatogonia; P, pachytene primary spermatocyte; S, Sertoli cell; L, Leydig cell; Ma, macrophage; ap, apoptosis; BV, blood vessel; V, vacuole; Int, interstitium. Bar: $12 \mu \mathrm{m}$.

study (Prabhu et al. 2006). KIT protein was not detectable in the type $\mathrm{A}$ spermatogonia of $\mathrm{LBNF}_{1}$ rats, although in situ hybridization analysis showed that Kit mRNA was present. Prabhu et al. (2006) did detect KIT protein in the spermatogonia stimulated to differentiate after 4 weeks of hormone suppression, correlating with our observations of more KIT-positive cells at that time and the presence of more B spermatogonia. We attribute the differences between the studies to the greater sensitivity the present method. From our results, we conclude that some of the type A spermatogonia in the irradiated testis have KIT, and therefore, the block to spermatogonial differentiation is not due to the absence of a defect in spermatogonia involving the absence of the KIT receptor.
As the presence of healthy $A_{\text {und }}$ spermatogonia after irradiation must be the source of the subsequent spermatogenesis recovery in the rat testis and radiation can produce spermatogonial DNA damage, it is essential to verify whether the remaining spermatogonial cells after irradiation are healthy and proliferative. We therefore assessed the presence of $M C M 7$, a protein that is part of a complex essential for chromosomal DNA replication (Pacek \& Walter 2004). In control animals, we confirmed that MCM7 is primarily expressed in spermatogonia and early primary spermatocytes (Com et al. 2006). In irradiated animals, the numbers of MCM7-positive spermatogonia indicated that all the surviving spermatogonia were expressing MCM7 and 

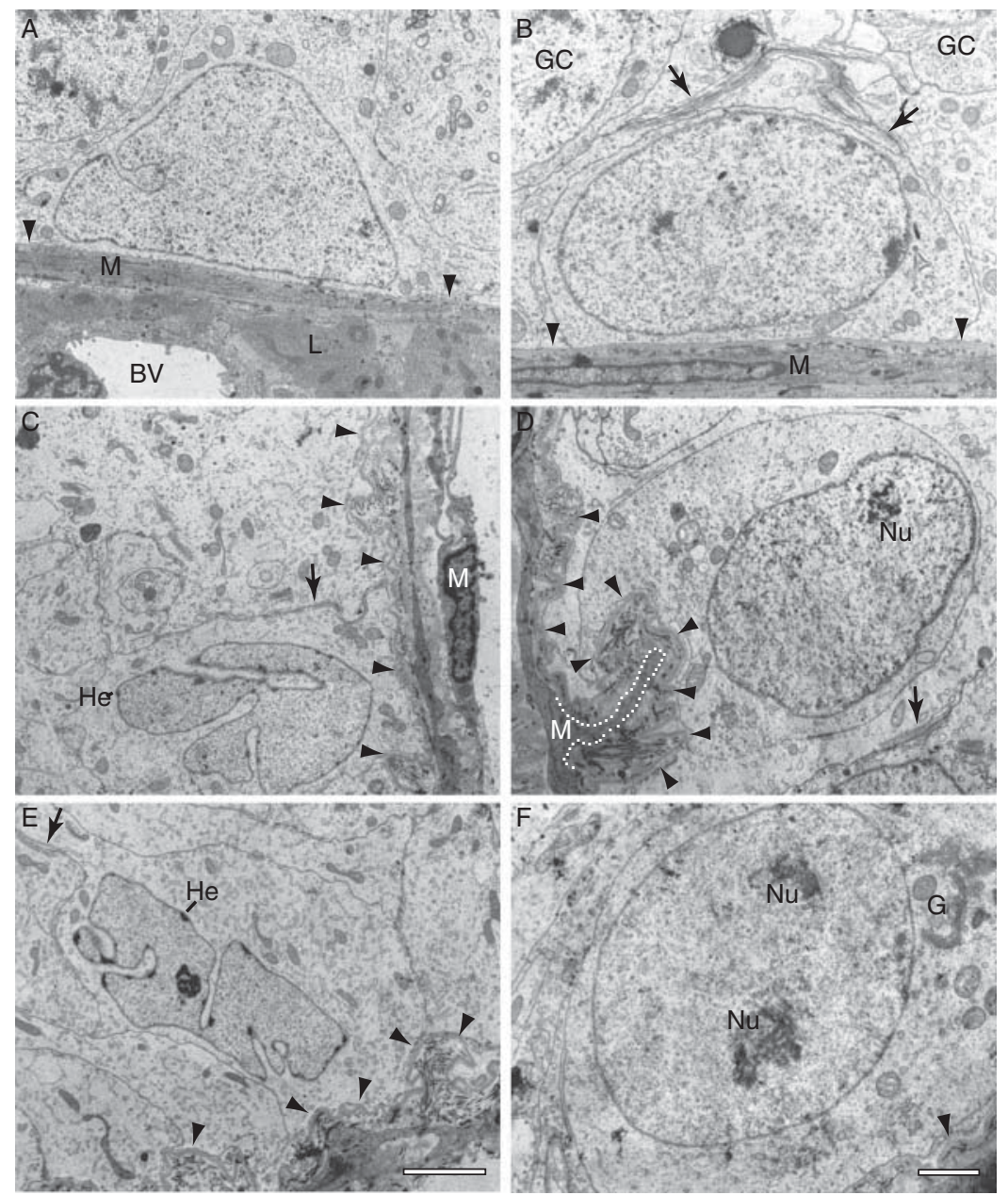

Figure 7 Electron micrographs of the basal region of tubules from control (A and B), irradiated-only ( $C$ and $D$ ), and 4-week hormone-suppressed ( $E$ and $F$ ) rats. (A, C, and E) Basal region of Sertoli cells. The Sertoli cell nuclei in the irradiated and hormonesuppressed rats are highly infolded with small spots of heterochromatin $(\mathrm{He})$ adherent to nuclear envelope. Arrows, Sertoli-Sertoli ectoplasmic specialization; arrowheads basal membrane. (B) type $\mathrm{A}_{\mathrm{al}}$ spermatogonia, (D) type $A_{1}$ spermatogonia, and $(F)$ type $A_{2}$ spermatogonia. In $\mathrm{D}$, a portion of the basal lamina and the cytoplasm of a myoid cell (white dots) are folded into the seminiferous epithelium. GC, germ cell (spermatocytes); M, myoid cell; BV, blood vessel; L, Leydig cell; $\mathrm{Nu}$, nucleolus; G, Golgi apparatus; Bars: A, C, and E: $3 \mu \mathrm{m} ; \mathrm{B}, \mathrm{D}$, and F: $1.5 \mu \mathrm{m}$. were not defective in proliferation. When irradiation was subsequently followed by hormone suppression, the numbers of MCM7-positive cells increased along with the numbers of spermatogonia confirming that the $A_{\text {und }}$ and differentiating spermatogonia were proliferative.

Evidence has accumulated from previous studies that the action of hormones mediating the radiation-induced block in spermatogonial differentiation occurs through the somatic cells. Specifically, the endogenous hormone primarily responsible for the inhibition of spermatogonial differentiation in irradiated treated rats was testosterone, although FSH had a minor inhibitory effect (Shetty et al. 2006). Because germ cells lack both androgen and FSH receptors, the block in spermatogonial differentiation, which is reversed by suppression of these hormones after irradiation, must involve the somatic cells (Meistrich et al. 2004), probably Sertoli, peritubular myoid, or Leydig cells because they express androgen receptor, and definitely the Sertoli cells, which are the only ones with FSH receptor. Reciprocal spermatogonial transplantation experiments have shown functionally that the defect caused by irradiation in the rat testes that results in the block of spermatogonial differentiation must be due to injury to the somatic compartment, not the germ cells (Zhang et al. 2007). Furthermore, they have also shown that the transplantation of Sertoli cells from normal immature rats into the interstitium of testes of irradiated rats stimulates partial recovery of endogenous spermatogenesis (Zhang et al. 2009).

Further evidence that hormone suppression induces changes in the somatic environment is provided by our observations that testicular weights and seminiferous tubular diameters progressively decrease during 6 weeks of hormone suppression despite increases in germ cell numbers. The weight loss during hormone suppression can be attributed to decreases in somatic cell tissue mass (Meistrich et al. 2001) as well as both interstitial and seminiferous tubule fluids (Porter et al. 2006).

The somatic cell that is the most likely candidate for mediating hormonal regulation of spermatogonial differentiation appeared to be the Sertoli cell, due to its juxtacrine, in addition to paracrine, interactions with the germ cells. First, it was important to ensure that the Sertoli cell number was not changed after irradiation. Previously, using a more basic counting method, the number of Sertoli cells per tubule cross section was 
shown to be unaffected by irradiation (Kangasniemi et al. 1996) or by hormone suppression after irradiation (Shuttlesworth et al. 2000). Since that method was subject to uncertainties due to tubular shrinkage, we directly showed here by stereological analysis that the total number of Sertoli cells per testis was unchanged after irradiation. However, ultrastructurally, we did observe changes in the Sertoli cell nuclei after irradiation, as they showed small spots of heterochromatin adherent to nuclear envelope and became highly infolded, as previously described after radiation (Topcu-Tarladacalisir \& Kanter 2009), but the significance of these changes is not known.

We next examined two factors, KITL and GDNF, produced by Sertoli cells that are known to regulate spermatogonial self-renewal and differentiation. KITL is a required for maintenance of KIT-positive differentiating germ cells and is expressed as a soluble form or as a membrane-bound isoform that is believed to have greater activity toward spermatogonial differentiation (Majumdar et al. 1994). Qualitatively, the level of KITL fluorescence in Sertoli cells appeared at least as high after irradiation as before, and quantitative results demonstrated no significant changes in KITL protein concentrations after hormone suppression of the irradiated rats. This is not inconsistent with previous in vivo observations using more precise microarray analyses of about a twofold increase in Kitl mRNA with irradiation, a 1.4-fold increase with testosterone suppression, but no effect of FSH (Zhou et al. 2010). In another in vivo model, after induction of a block in A spermatogonial differentiation with a chemical hexanedione, there was a decrease in the proportion of $\mathrm{Kitl} \mathrm{mRNA}$ in the membrane-bound form relative to the soluble form, indicating that KITL may be less able to stimulate spermatogonial differentiation (Blanchard et al. 1998). However, our results at the protein level, using a C-terminal antibody, which is specific for the membrane form of KTILG, clearly show no significant change in the more active form of KITL resulting from hormone suppression. As, we observed KIT-positive A spermatogonia and KITL protein expression in irradiated-only animals, and KITL protein expression did not change with hormone suppression, we can presume that deficiencies in KITL-KIT system are not responsible for the block in spermatogonial differentiation after irradiation, and changes in the activity of this system are not involved in the increase in spermatogonial differentiation after hormone suppression. This is consistent with other observations that hormonal suppression with a GNRH analog stimulated the proliferation and/or survival of the early-stage type $\mathrm{A}$ spermatogonia even in mutant mice that lack the active form of KITL (Ohmura et al. 2003).

GDNF, another Sertoli cell factor known to affect spermatogonial proliferation and differentiation, continues to be well-expressed in irradiated rats. A recent study has indicated that the cyclical changes in GDNF expression by Sertoli cells under normal conditions are responsible for the stage-specific replication and differentiation of stem spermatogonia (Johnston et al. 2011). Although control animals showed stage-specific fluorescence, in irradiated-only animals, we showed that GDNF protein concentrations appear to be same in all tubules as there is no longer a seminiferous epithelial cycle and the expression of other normally cyclical Sertoli cell proteins is similar in all tubules (Maiti et al. 2001). Following hormone suppression of the irradiated rats, we do observe increases in GDNF protein concentration, which became significant after 4 weeks of treatment. This result differs from those included in a previous report (Tadokoro et al. 2002) that in mouse testes with blocked spermatogonial differentiation, hormone suppression decreased Gdnf mRNA levels. Our result showing a progressive increase in GDNF expression from 3 days up to 4 weeks of hormone suppression correlate with the increase in type $A_{\text {und }}$ spermatogonia. The current model is that GDNF, which is essential for stem spermatogonial survival in vitro, enhances stem and/or $\mathrm{A}_{\text {und }}$ spermatogonial proliferation in vivo but negatively regulates their differentiation (Meng et al. 2000, Tadokoro et al. 2002, Johnston et al. 2011). Thus, the concentrations of GDNF, which should inhibit differentiation, do not appear to be a primary cause of the block in spermatogonial differentiation in irradiated rats or its reversal with hormone suppression. Furthermore, analysis of the mRNAs for the GDNF co-receptors on spermatogonia shows that Gfra1 mRNA decreases after irradiation and Ret increases after hormone suppression (Zhou et al. 2010), confirming that changes in the GDNF signaling system cannot be involved in the induction or reversal of the spermatogonial differentiation block.

Currently, little is known about specific effects of the peritubular myoid cells and the basement membrane on spermatogonia proliferation and differentiation. We did observe small invaginations of the basal lamina into Sertoli cells that could be merely a consequence of the tubular shrinkage. Rarely, larger protrusions into $A_{1}$ spermatogonia that were only attached to the basement membrane at the protrusion were observed and may be a first sign the death of the spermatogonia.

Based on observations that the genes most strongly increased after irradiation and downregulated by androgen suppression in the somatic cells of rat testes were in the Leydig cells (Zhou et al. 2010, 2011), we further investigated the role of Leydig cells in the spermatogonial differentiation block by injecting EDS into irradiated rats at the beginning of the hormone suppression treatment. The loss of Leydig cells produced by EDS, in addition to hormonal suppression, produced rapid recovery of spermatogenesis resulting in almost the same numbers of differentiating spermatogonia within 1 week as produced by 2 weeks of hormone suppression alone. Other studies showed that the stimulation after X(EDS)AF treatment for 2 weeks resulted in recovery of 
spermatogenesis (spermatocytes and numerous B spermatogonia) in $70 \%$ of the tubules contained were observed, compared with only $0.5 \%$ of tubules observed with XAF alone for 2 weeks (G Shetty, manuscript in preparation). By contrast, a previous report indicated that EDS treatment of rats with a spermatogonial block induced by hexanedione inhibited the hormonesuppression-induced recovery of spermatogonial differentiation (Richburg et al. 2002). Our results clearly show that Leydig cells are not required for reinitiation of spermatogonial differentiation by hormone suppression of irradiated rats; and it seems that Leydig cells might even inhibit the recovery, but further studies are required to confirm that suggestion.

Development of methods to minimize or reverse the gonadal toxicity of radiation and chemotherapy is of great importance for the preservation of fertility of young male cancer patients. In particular, gonadotropin and testosterone suppression have been widely demonstrated in rodent studies to promote the survival and differentiation of endogenous surviving spermatogonia as well as to enhance the colonization and differentiation of transplanted spermatogonial stem cells (Meistrich et al. 1999, Ohmura et al. 2003, Zhang et al. 2007, Wang et al. 2010). Although the application of hormone suppression treatment to enhance endogenous spermatogenic recovery has so far been successful in only one of eight clinical trials (reviewed in Shetty \& Meistrich (2005)), it appears to be more promising for future clinical trials involving transplantation of cryopreserved stem cells. However, as hormone suppression has multiple side effects and the stimulation of recovery occurs gradually, it would be preferable to specifically target the downstream genes or pathways that are directly responsible for the block in spermatogonial differentiation. This study has shown that the two most obvious Sertoli cell factors are not involved in mediating the hormone-induced inhibition of spermatogonial differentiation in irradiated testes. Future studies in animal systems are needed to determine the cells (possibly the Leydig cells) and factors that block spermatogonial recovery after radiation and chemotherapy and eventually to translate the results to promote recovery of spermatogenesis in patients with cancer.

\section{Supplementary data}

This is linked to the online version of the paper at http://dx. doi.org/10.1530/REP-12-0494.

\section{Declaration of interest}

The authors declare that there is no conflict of interest that could be perceived as prejudicing the impartiality of the research reported.

\section{Funding}

This study was supported in part by the following Brazilian Foundations: Coordenação de Aperfeiçoamento de Pessoal de Nível Superior (CAPES), Fundação de Amparo à Pesquisa do Estado de Minas Gerais (FAPEMIG), and Conselho Nacional de Pesquisa (CNPq). Electron microscopic analyzes were developed at Capi facility - Centro de Aquisição e Processamento de Imagens do ICB-UFMG.

\section{Acknowledgements}

The authors thank Maria Luiza da Silva for assistance with histological preparations.

\section{References}

Abercrombie M 1946 Estimation of nuclear population from microtome sections. Anatomical Record 94 39-47. (doi:10.1002/ar.1090940210)

Bartlett JMS, Kerr JB \& Sharpe RM 1986 The effect of selective destruction and regeneration of rat Leydig cells on the intratesticular distribution of testosterone and morphology of the seminiferous epithelium. Journal of Andrology 7 240-253. (doi:10.1002/j.1939-4640.1986.tb00924.x)

Blanchard KT, Lee J \& Boekelheide K 1998 Leuprolide, a gonadotropinreleasing hormone agonist, reestablishes spermatogenesis after 2.5hexanedione-induced irreversible testosterone injury in the rat, resulting in normalized stem cell factor expression. Endocrinology 139 236-244. (doi:10.1210/en.139.1.236)

Chiarini-Garcia H \& Meistrich ML 2008 High-resolution light microscopic characterization of spermatogonia. Methods in Molecular Biology 450 95-107. (doi:10.1007/978-1-60327-214-8_6)

Chiarini-Garcia H \& Russell LD 2002 Characterization of mouse spermatogonia by transmission electron microscopy. Reproduction 123 567-577. (doi:10.1530/rep.0.1230567)

Chiarini-Garcia H, Raymer AM \& Russell LD 2003 Non-random distribution of spermatogonia in rats: evidence of niches in the seminiferous tubules. Reproduction 126 669-680. (doi:10.1530/rep.0.1260669)

Chiarini-Garcia H, Parreira GG \& Almeida FR 2011 Glycol methacrylate embedding for improved morphological, morphometrical, and immunohisto chemical investigations under light microscopy: testes as a model. Methods in Molecular Biology 689 3-18. (doi:10.1007/978-1-60761-950-5_1)

Com E, Rolland AD, Guerrois M, Aubry F, Jégou B, Vallet-Erdtmann V \& Pineau C 2006 Identification, molecular cloning, and cellular distribution of the rat homolog of minichromosome maintenance protein 7 (MCM7) in the rat testis. Molecular Reproduction and Development 73 866-877. (doi:10.1002/mrd.20453)

Deshpande S, Agosti V, Manova K, Moore MA, Hardy MP \& Besmer P 2010 Kit ligand cytoplasmic domain is essential for basolateral sorting in vivo and as roles in spermatogenesis and hematopoiesis. Developmental Biology 337 199-210. (doi:10.1016/j.ydbio.2009.10.022)

Drumond AL, Meistrich ML \& Chiarini-Garcia H 2011 Spermatogonial morphology and kinetics during testis development in mice: a high resolution light microscopy approach. Reproduction 142 145-155. (doi:10.1530/REP-10-0431)

Dym M \& Clermont Y 1970 Role of spermatogonia in the repair of the seminiferous epithelium following $\mathrm{X}$-irradiation of the rat testis. American Journal of Anatomy 128 265-282. (doi:10.1002/aja.1001280302)

Fossa MD \& Magelssen H 2004 Fertility and reproduction after chemotherapy of adult cancer patients: malignant lymphoma and testicular cancer. Annals of Oncology 15 (Suppl 4) iv256-iv259. (doi:1093/annonc/mdh936)

Johnston DS, Olivas E, DiCandeloro P \& Wright WW 2011 Stage-specific changes in GDNF expression by rat Sertoli cells: a possible regulator of the replication and differentiation of stem spermatogonia. Biology of Reproduction 85 763-769. (doi:10.1095/biolreprod.110.087676)

Kangasniemi M, Veromaa TI, Kulmala J, Kaipia A, Parvinen M \& Toppari I 1990 DNA-flow cytometry of defined stages of rat seminiferous epithelium: effects of $3 \mathrm{~Gy}$ of high-energy X-irradiation. Journal of Andrology 11 312-317. (doi:10.1002/j.1939-4640.1990.tb03246.x) 
Kangasniemi M, Huhtaniemi I \& Meistrich ML 1996 Failure of spermatogenesis to recover despite the presence of a spermatogonia in the irradiated LBNF1 rat. Biology of Reproduction 54 1200-1208. (doi:10.1095/biolreprod54.6.1200)

Latendresse JR, Warbrittion AR, Jonassen H \& Creasy DM 2002 Fixation of testes and eyes using a modified Davidson's fluid: comparison with Bouin's fluid and conventional Davidson's fluid. Toxicologic Pathology 30 524-533. (doi:10.1080/01926230290105721)

Lu CC \& Meistrich ML 1979 Cytotoxic effects of chemotherapeutic drugs on mouse testis cells. Cancer Research 39 3575-3582.

Maiti S, Meistrich ML, Wilson G, Shetty G, Marcelli M, McPhaul MJ, Morris PL \& Wilkinson MF 2001 Irradiation selectively inhibits expression from the androgen-dependent Pem homeobox gene promoter in Sertoli cells. Endocrinology 142 1567-1577. (doi:10.1210/en.142.4.1567)

Majumdar MK, Fen L, Medlock E, Toksoz D \& Williams DA 1994 Identification and mutation of primary and secondary proteolytic cleavage sites in murine stem cell factor cDNA yields biologically active, cell-associated protein. Journal of Biological Chemistry 269 1237-1242.

Meistrich ML \& Kangasniemi M 1997 Hormone treatment after irradiation stimulates recovery of rat spermatogenesis from surviving spermatogonia. Journal of Andrology 18 80-87. (doi:10.1002/j.1939-4640.1997.tb01879.x)

Meistrich ML \& Shetty G 2003 Inhibition of spermatogonial differentiation by testosterone. Journal of Andrology 24 135-148. (doi:10.1002/j.19394640.2003.tb02652.x)

Meistrich ML, Wilson G \& Huhtaniemi I 1999 Hormonal treatment after cytotoxic therapy stimulates recovery of spermatogenesis. Cancer Research 59 3557-3560.

Meistrich ML, Wilson G, Shuttlesworth G, Huhtaniemi I \& Reissmann T $2001 \mathrm{GnRH}$ agonists and antagonists stimulate recovery of fertility in irradiated LBNF1 rats. Journal of Andrology 22 809-817. (doi:10.1002/j. 1939-4640.2001.tb02585.x)

Meistrich ML, Shetty G, Bolden-Tiller OU \& Porter KL 2004 Hormones and spermatogonial development. In Sertoli Cell Biology, ch 23, pp 437-48. Eds MK Skinner \& MD Griswold. San Diego: Elsevier Academic Press.

Meistrich ML, Vassilopoulou-Sellin R \& Lipshultz LI 2005 Gonadal dysfunction. In Cancer: Principles and Practice of Oncology, 7th edn, pp 2560-2574, Eds VT DeVita, S Hellman \& SA Rosenberg. Philadelphia: Lippincott Williams \& Wilkins.

Meng X, Lindahl M, Hyvonen ME, Parvinen M, de Rooij DG, Hess MW, Raatikainen-Ahokas A, Sainio K, Rauvala H, Lakso M et al. 2000 Regulation of cell fate decision of undifferentiated spermatogonia by GDNF. Science 287 1489-1493. (doi:10.1126/science.287.5457.1489)

Ohmura $M$, Ogawa $T$, Ono $M$, Dezawa $M$, Hosaka $M$, Kubota $Y$ \& Sawada H 2003 Increment of murine spermatogonial cell number by gonadotropin-releasing hormone analogue is dependent of stem cell factor c-kit signal. Biology of Reproduction 68 2304-2313. (doi:10.1095/ biolreprod.102.013276)

Ohta H, Yomogida K, Dohmae K \& Nishimune Y 2000 Regulation of proliferation and differentiation in spermatogonial stem cells: the role of c-kit and its ligand SCF. Development 127 2125-2131.

Pacek M \& Walter JC 2004 A requirement for MCM7 and Cdc45 in chromosome unwinding during eukaryotic DNA replication. EMBO Journal 23 3667-3676. (doi:10.1038/sj.emboj.7600369)

Porter KL, Shetty G \& Meistrich ML 2006 Testicular edema is associated with spermatogonial arrest in irradiated rats. Endocrinology 147 1297-1305. (doi:10.1210/en.2005-0890)

Porter KL, Shetty G, Shuttlesworth GA, Weng CC, Huhtaniemi I, Pakarinen P \& Meistrich ML 2009 Estrogen enhances recovery from radiation-induced spermatogonial arrest in rat testes. Journal of Andrology 30 440-451. (doi:10.2164/jandrol.108.006635)

Prabhu SM, Meistrich ML, McLaughlin EA, Roman SD, Warne S, Mendis S, Itman C \& Loveland KL 2006 Expression of C-Kit receptor mRNA and protein in the developing, adult and irradiated rodent testis. Reproduction 131 489-499. (doi:10.1530/rep.1.00968)
Richburg JH, Johnson KJ, Schoenfeld HA, Meistrich ML \& Dix DJ 2002 Defining the cellular and molecular mechanisms of toxicant action in the testis. Toxicology Letters 135 167-183. (doi:10.1016/S0378-4274(02)00254-0)

de Rooij DG 1998 Stem cells in the testis. International Journal of Experimental Pathology 79 67-80. (doi:10.1046/j.1365-2613.1998. 00057.x)

Shetty G \& Meistrich ML 2005 Hormonal approaches to preservation and restoration of male fertility after cancer treatment. Journal of the National Cancer Institute. Monographs 34 36-39. (doi:10.1093/jncimonographs/ lgi002)

Shetty G, Weng CCY, Meachem SJ, Bolden-Tiller OU, Zhang Z, Pakarinen P, Huhtaniemi IE \& Meistrich ML 2006 Both testosterone and follicle-stimulating hormone independently inhibit spermatogonial differentiation in irradiated rats. Endocrinology 147 472-482. (doi:10.1210/en.2005-0984)

Shuttlesworth GA, de Rooij DG, Huhtaniemi I, Reissmann T, Russell LD, Shetty G, Wilson G \& Meistrich ML 2000 Enhancement of A spermatogonial proliferation and differentiation in irradiated rats by gonadotropin-releasing hormone antagonist administration. Endocrinology 141 37-49. (doi:10.1210/en.141.1.37)

Sinha Hikim AP, Bartke A \& Russell LD 1988 Morphometric studies on hamster testes in gonadally active and inactive states: light microscope findings. Biology of Reproduction 39 1225-1237. (doi:10.1095/biolreprod39.5.1225)

Tadokoro Y, Yomogida K, Ohta H, Tohda A \& Nishimune Y 2002 Homeostatic regulation of germinal stem cell proliferation by the GDNF/FSH pathway. Mechanisms of Development 113 29-39. (doi:10.1016/S0925-4773(02)00004-7)

Topcu-Tarladacalisir Y \& Kanter M 2009 Role of L-carnitine in the prevention of seminiferous tubules damage induced by gamma radiation: a light and electron microscopic study. Archives of Toxicology 83 735-746. (doi:10.1007/s00204-008-0382-y)

Wang G, Shao SH, Weng CC, Wei C \& Meistrich ML 2010 Hormonal suppression restores fertility in irradiated mice from both endogenous and donor-derived stem spermatogonia. Toxicological Sciences 117 225-237. (doi:10.1093/toxsci/kfq191)

Zhang Z, Shao S \& Meistrich ML 2007 The radiation-induced block in spermatogonial differentiation is due to damage to the somatic environment, not the germ cells. Journal Cellular Physiology $\mathbf{2 1 1}$ 149-158. (doi:10.1002/jcp.20910)

Zhang Z, Shao S, Shetty G \& Meistrich ML 2009 Donor Sertoli cells transplanted into irradiated rat testes stimulate partial recovery of endogenous spermatogenesis. Reproduction 137 497-508. (doi:10. 1530/REP-08-0120)

Zhou W, Bolden-Tiller OU, Shetty G, Shao SH, Weng CC, Pakarinen P, Liu Z, Stivers DN \& Meistrich ML 2010 Changes in gene expression in somatic cells of rat testes resulting from hormonal modulation and radiation-induced germ cell depletion. Biology of Reproduction 82 54-65. (doi:10.1095/biolreprod.109.078048)

Zhou W, Bolden-Tiller OU, Shao SH, Weng CC, Shetty G, AbuElhija M, Pakarinen P, Huhtaniemi I, Momin AA, Wang J et al. 2011 Estrogenregulated genes in rat testes and their relationship to recovery of spermatogenesis after irradiation. Biology of Reproduction 85 823-833. (doi:10.1095/biolreprod.111.091611)

Received 5 December 2012

First decision 14 January 2013

Revised manuscript received 9 June 2013

Accepted 23 July 2013 